\section{(C) OPEN ACCESS}

\begin{abstract}
- Additional material is published online only. To view please visit the journal online (http://dx.doi.org/10.1136/ oemed-2018-105647).

${ }^{1}$ Finnish Institute of Occupational Health, Helsinki, Finland

${ }^{2}$ Department of Physical and Rehabilitation Medicine, Helsinki University Hospital, Helsinki,

Finland

${ }^{3}$ University of Helsinki, Helsinki Finland
\end{abstract}

\section{Correspondence to}

Maria Sirén, Finnish Institute of Occupational Health, Helsinki, Finland; maria.siren@hus.fi

Received 13 December 2018 Revised 11 February 2019 Accepted 25 February 2019 Published Online First 30 March 2019

\title{
Work participation and working life expectancy after a disabling shoulder lesion
}

\author{
Maria Sirén, ${ }^{1,2}$ Eira Viikari-Juntura, ${ }^{1}$ Jari Arokoski, ${ }^{2,3}$ Svetlana Solovieva ${ }^{1}$
}

ABSTRACT
Objective To

Objective To examine the impact of a disabling nontraumatic shoulder lesion on work participation and working life expectancy.

Methods From a 70\% random sample of the Finnish population, we selected 30-59-year-old wage earners with prolonged sickness absence due to a shoulder lesion $(n=7644)$. We followed the persons from 2006 to 2014 and calculated the proportion of time a person spent in different work participation statuses. The associations of potential determinants with a preterm exit from paid employment were tested using Cox regression. Years expected to be spent in different work participation statuses were estimated applying the Sullivan method for healthy life expectancy.

Results During 9 years of follow-up time spent at work was reduced from $77.7 \%$ to $46.7 \%$, and $15.8 \%$ of the persons were granted disability retirement, mostly due to shoulder and other musculoskeletal diseases. Compared with the general population persons with a disabling shoulder disease are expected to lose from 1.8 to 8.1 years of working life, depending on their age. Age, gender, education, duration of initial sickness absence due to the shoulder lesion, not being able to return to work sustainably and participation in vocational rehabilitation predicted preterm exit from work. Heavy lifting increased the risk of preterm exit marginally. Conclusions Working life expectancy is markedly reduced in persons with a disabling shoulder lesion, mainly because of disability retirement due to musculoskeletal problems. Clinicians should consider interventions targeted at improving musculoskeletal functioning and necessary work modifications before shoulder problems become chronic or the persons develop disabling comorbid musculoskeletal conditions.

\section{INTRODUCTION}

Shoulder pain is the fifth most common cause of musculoskeletal consultation in primary care among persons aged $25-64$ years $^{1}$. It is known to cause suffering for the individual and result in work disability and significant healthcare costs. ${ }^{2} 3$ In a systematic review, the 1-year prevalence of shoulder pain in the general population varied from $4.7 \%$ to $46.7 \%$ and the lifetime prevalence up to $66.7 \%{ }^{4}$ Rotator cuff tendinopathy is the underlying cause of the pain approximately in two of three cases. ${ }^{5}$ Because the pathomechanism is usually degenerative, shoulder complaints are rare under the age of 25 years and become more common with age, reaching the incidence peak at the age of 45-64 years ${ }^{6}$.

\section{Key messages}

What is already known about this subject?

- Shoulder lesions are common and cause remarkable suffering for the affected person and a burden to the society. The impact of non-traumatic shoulder lesions on work participation is largely unknown, however.

\section{What are the new findings?}

- In total, $15.8 \%$ of persons with prolonged work disability due to a shoulder lesion were granted disability retirement during 9 years, largely due to comorbid musculoskeletal problems in addition to shoulder diseases. For persons with prolonged work disability due to a shoulder lesion, working life years are reduced by 1.8 to 8.1 years as compared with the general population.

\section{How might this impact on policy or clinical practice in the foreseeable future? \\ - Interventions targeted at improving musculoskeletal functioning and necessary work modifications need to be implemented for persons with a shoulder lesion before their shoulder problems become chronic or the persons develop disabling comorbid conditions.}

Approximately half of the persons with shoulder pain experience persistent or recurrent pain after 6 months and $41 \%$ after 1 year. ${ }^{78}$ Prolonged shoulder pain may have an impact on work participation and work retention. Nevertheless, little is known about work disability and work participation in persons with shoulder problems. In one study, $16 \%$ of workers with a new episode of shoulder pain reported $>10$ days of shoulder pain related sick leave in 6 months. ${ }^{9}$ According to a systematic review, a non-traumatic history, disease severity and previous sickness absence (SA) were significantly associated with delayed return to work (RTW) or future SA. ${ }^{10}$ In addition, in a 1-year follow-up study, low education was found to be the most consistent predictor of a poor outcome of work status. ${ }^{11}$

Within the musculoskeletal diseases, shoulder disorders (eg, degenerative shoulder lesions) were reported to be the second most common cause of SA after back disorders. ${ }^{12}$ In both genders, manual workers were found to have a substantially higher risk of a new SA episode than non-manual workers. Certain work-related risk factors (arm elevation, shoulder load, hand force exertion, hand-arm 


\begin{tabular}{|c|c|c|}
\hline & $\begin{array}{l}\text { Eligible study } \\
\text { population with } \\
\text { shoulder lesions } \\
(\mathrm{n}=7644)\end{array}$ & $\begin{array}{l}\text { Study base } \\
\text { Employed or self-employed } \\
\text { on } 1 \text { January } 2006 \\
(n=1210231)\end{array}$ \\
\hline Age group (years) (\%) & 48.4 (48.3 to 48.5$)$ & 44.70 (44.68 to 48.71$)$ \\
\hline $30-39$ & 14.0 & 31.0 \\
\hline $40-49$ & 35.9 & 35.8 \\
\hline 50-59 & 50.1 & 33.2 \\
\hline \multicolumn{3}{|l|}{ Gender (\%) } \\
\hline Women & 55.8 & 50.0 \\
\hline \multicolumn{3}{|l|}{ Education (\%) } \\
\hline Primary & 28.1 & 17.6 \\
\hline Secondary & 53.8 & 42.0 \\
\hline Tertiary & 18.1 & 40.5 \\
\hline \multicolumn{3}{|l|}{ Region of Finland } \\
\hline Southern & 22.6 & 30.5 \\
\hline Western & 22.3 & 22.2 \\
\hline Eastern & 27.3 & 24.6 \\
\hline Northern & 27.6 & 22.7 \\
\hline \multicolumn{3}{|l|}{ Employment sector (\%) } \\
\hline Private, domestic & 48.3 & 54.6 \\
\hline Private, foreign & 8.6 & 8.3 \\
\hline Public & 40.5 & 33.9 \\
\hline Other & 2.6 & 3.2 \\
\hline \multicolumn{3}{|l|}{ Occupation (\%) } \\
\hline \multicolumn{3}{|l|}{ Upper-level non-manual occupations } \\
\hline Managers & 1.9 & 5.6 \\
\hline Professionals & 5.4 & 17.9 \\
\hline \multicolumn{3}{|l|}{ Lower-level non-manual occupations } \\
\hline Technicians & 11.8 & 19.2 \\
\hline Office and customer workers & 7.9 & 8.2 \\
\hline Service, care and sales workers & 20.1 & 15.1 \\
\hline \multicolumn{3}{|l|}{ Manual occupations } \\
\hline Agricultural workers & 5.2 & 4.2 \\
\hline Construction, metal and woodworkers & 16.2 & 11.7 \\
\hline Machine operators and assemblers & 16.3 & 10.4 \\
\hline Unskilled manual workers & 15.2 & 7.7 \\
\hline \multicolumn{3}{|l|}{ Work-related exposures (\%) } \\
\hline Heavy lifting & 21.9 & 14.8 \\
\hline $\begin{array}{l}\text { Working with hands above shoulder } \\
\text { level }\end{array}$ & 20.5 & 14.3 \\
\hline Work requiring high hand force & 31.7 & 20.6 \\
\hline High job demands & 37.1 & 36.8 \\
\hline Low job control & 71.9 & 53.8 \\
\hline
\end{tabular}

vibration and psychosocial demands) increase the incidence of subacromial pain. ${ }^{13}$ These physical and psychosocial work-related factors may delay RTW, cause future work disability and preterm exit from paid employment in persons with shoulder problems. Indeed, persons in physically demanding occupations are at a higher risk of SA or disability retirement due to any cause as well as due to musculoskeletal diseases than those in occupations with physically less demanding work tasks. ${ }^{14-17}$

A shoulder lesion can contribute to exit out of paid employment in many ways, but a full picture of these different routes has not been studied before. More knowledge is also needed for the determinants that may predispose persons with shoulder complaints to cease working. The aim of this study was to examine the impact of a disabling non-traumatic shoulder lesion on work participation over 9 years and working life expectancy. Moreover, we studied the determinants for preterm exit from paid employment.

\section{MATERIALS AND METHODS}

\section{Setting and data sources}

This was a population-based study, utilising register data from a $70 \%$ random sample of the Finnish population aged $18-70$ years living in Finland on 31 December 2004 ( 2.5 million). Included in the study were persons aged 30-59 years, who were employed or self-employed on 1 January 2006 and had received full-time SA benefit due to a shoulder lesion. We excluded persons who had a prior SA due to shoulder problems in 2005 or received any retirement-related benefits prior to 1 January 2006. Our cohort consisted of 7644 persons (3378 men and 4266 women), who were followed from the first day of their first SA due to a shoulder lesion in 2006 till 31 October 2014. A flow chart of the sample formation is presented in the online supplementary figure 1 .

The data included information on SA benefits, rehabilitation allowance and national pensions obtained from the Social Insurance Institution of Finland (SII); employment periods and earnings-related pensions from the Finnish Centre for Pensions (FCP), and on sociodemographic factors and occupational history from the Finnish Longitudinal Employer-Employee Data (FLEED) of Statistics Finland. Date of death from the Population Information System was provided to the study by the SII.

\section{Health-related and social benefits Sickness absence}

The register of the SII provides information on the start and end dates as well as primary diagnoses for all compensated full SA spells and all part time SA spells. The first 10 days of full SA are paid by the employer and are not registered. Full-time SA days are compensated from the 11th day, and all part-time SA days are compensated from the first day. The diagnoses were classified according to the International Statistical Classification of Diseases and Related Health Problems, 10th Revision (ICD-10, the Finnish version of ICD-classification 1996). The diagnoses of primary interest for this study were M75 (shoulder lesions, including for instance impingement syndrome, rotator cuff tear or rupture and adhesive capsulitis).

\section{Disability retirement}

In Finland, a disability pension may be granted as full or partial, depending on the degree of decreased work ability. If there is a possibility to restore the employee's work ability through rehabilitation or treatment, a temporary pension for a fixed period can be granted by the pension provider. Temporary disability pension can be continued after an initial period; however, a decision regarding permanent disability pension is made within 2 years. The FCP register provides information on all disability retirement events (full or partial, permanent or temporary), with their primary and secondary diagnoses, which are classified according to the ICD-10 (Finnish version of ICD-classification 1996).

\section{Employment and unemployment}

All employment and unemployment periods with their start and end dates were provided by the register of the FCP and the FLEED.

\section{Rehabilitation allowance}

The registers of the FCP and SII provided information on the start and end dates of the vocational rehabilitation periods. 


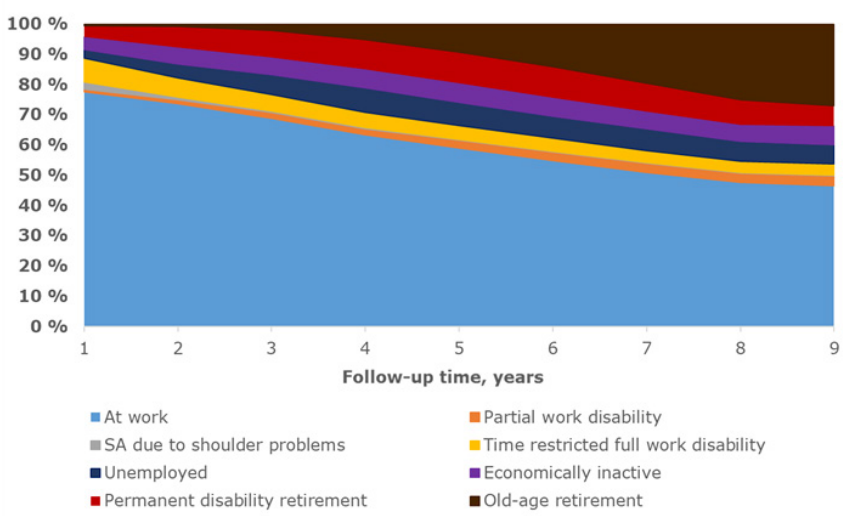

Figure 1 Time spent during follow-up in different work participation statuses after prolonged SA due to a shoulder lesion. The work participation statuses are: (1) at work (having employment and not receiving any benefit), (2) on partial work disability (receiving partial work disability benefit, including part time SA and partial disability retirement), (3) on SA due to a shoulder lesion (receiving full-time SA benefit), (4) on time restricted full-time work disability (receiving a full-time, ill-healthrelated benefit paid for a restricted time period, including SA benefit due to other reason than shoulder lesion, temporary disability retirement and vocational rehabilitation), (5) unemployed, (6) economically inactive (not at work and not receiving ill-health related or unemployment benefit, or pension), (7) on permanent disability retirement, and (8) on old age retirement. SA, sickness absence.

\section{Predictor variables}

Sociodemographic factors and occupational history

The persons' geographic region, level of education, annual income, occupation and employment sector were obtained from the FLEED based on information measured in 2005. Geographic region consisted of (1) Southern Finland, (2) Western Finland or Åland, (3) Eastern Finland and (4) Northern Finland. Level of education was defined as (1) higher or lower tertiary $(>12$ years), (2) secondary (9-12 years) or (3) primary ( $<9$ years). Employment sector was classified as (1) public, (2) private or (3) other, including self-employment. The occupations were classified using the Classification of Occupations 2001 by Statistics Finland, which is based on the International Standard Classification of Occupations (ISCO-88). Only major (1-digit level) occupational groups were used in the analysis. Income consisted of both wage and capital income of the individual and was categorised into tertiles (high, medium and low).

\section{Physical and psychosocial work-related factors}

Working with hands above shoulder level, manual handling of heavy loads (heavy lifting), forceful hand movements, high job demands and low job control were estimated with gender-specific job exposure matrices. ${ }^{18} 19$

\section{Work participation statuses}

We focused on eight work participation statuses: (1) at work (having employment and not receiving any benefit), (2) on partial work disability (receiving partial work disability benefit, including part-time SA and partial disability retirement), (3) on SA due to a shoulder lesion (receiving full-time SA benefit), (4) on time-restricted full-time work disability (receiving a fulltime, ill-health-related benefit paid for a restricted time period, including SA benefit due to other reason than shoulder lesion, temporary disability retirement and vocational rehabilitation), (5) unemployed, (6) economically inactive (not at work and not receiving ill-health-related or unemployment benefit, or pension), (7) on permanent disability retirement and (8) on old-age retirement.

\section{Outcomes}

We defined a sustained RTW as returning to regular duties for a minimum of 28 consecutive days immediately following SA.

Time spent in different work participation statuses. Based on daily work participation statuses, we calculated the proportion of time a person spent in each status for each year of the follow-up. The follow-up started from the day following the last day of the SA until death, permanent retirement or 31 October 2014, whichever came first.

Preterm exit from paid employment was defined as transiting to permanent disability retirement or old-age retirement prior to the age of 63 years.

Years expected to be spent in different work participation statuses until the official retirement age (63 years) were calculated. The calculations were carried out for the following statuses: at work; on ill-health-related benefit while employed; temporarily out of work due to being unemployed or economically inactive; permanently retired, including full disability retirement and preterm old-age retirement.

\section{Statistical analysis}

We used Kaplan-Meier analysis to plot sustained RTW curves. The follow-up started on the first compensated day of SA due to a shoulder lesion and continued until the last day of SA. The follow-up time was counted in days. We assessed visually the proportional hazard assumption through inspection of the log-log hazards plots and found it to be satisfactory.

We estimated the associations of potential determinants (gender, age [years], duration of index SA due to the shoulder lesion, education, geographic region, sector of employment, income, physical and psychosocial work-related factors, sustained RTW and participation in vocational rehabilitation during follow-up) with preterm exit from paid employment applying Cox proportional hazards regression analysis and reported them as relative risks (RRs) with 95\% CIs. First, age and gender were adjusted for in all the analyses (model 1). Model 2 was a full model mutually adjusted for all covariates. When model 1 and model 2 produced different associations between a potential determinant and preterm exit from paid employment, we performed a sensitivity analysis to confirm the association. For this, we tested several Cox models, where all further covariates were added in model 1 one by one.

We adopted the Sullivan method for healthy life expectancy ${ }^{20}$ to calculate years expected to be spent in different work participation statuses. These calculations were carried out for the age range 30-55 years, corresponding to our study population at baseline and plotted in 5-year intervals. We used age-specific retirement rates at the ages of $30,35,40,45,50$ and 55 years. Using the Sullivan method, we first generated period working life tables at the age of $\geq 30$. Second, we attributed years to different work participation statuses: at work; on ill-health-related benefit while having employment; temporarily out (unemployed or being economically inactive); permanently out (on permanent disability retirement or preterm old age retirement). The Sullivan method combines standard period life tables and period information on distributions of work participation statuses by single year of age. 
Table 2 Determinants of preterm (before 63 years) exit from paid employment after prolonged SA due to a shoulder lesion.

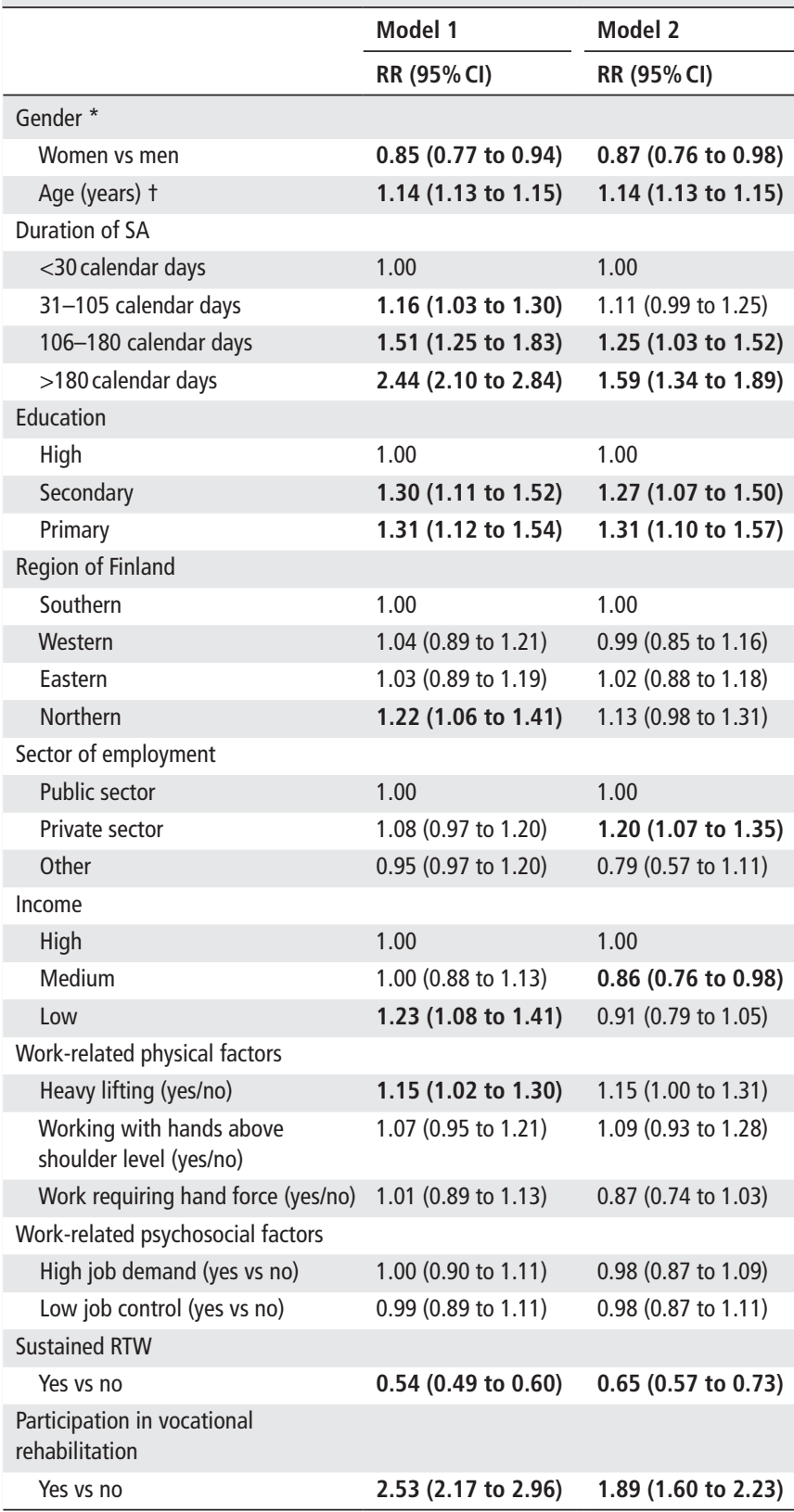

Model 1: RRs and their $95 \% \mathrm{Cl}$ are adjusted for gender and age.

Model 2: RRs and their $95 \% \mathrm{Cl}$ are mutually adjusted (adjusted for all variables in the table).

${ }^{*}$ Adjusted only for age.

†Adjusted only for gender.

$\mathrm{RR}$, relative risk; RTW, return to work; SA, sickness absence.

We compared the estimated working life expectancy (sum of the time expected to be spent at work and on ill-health related benefits while having employment) in persons with a disabling shoulder lesion with that in the general population. ${ }^{21}$

The SAS V.9.4 statistical software was used for the analyses.

\section{RESULTS}

The 1-year prevalence of prolonged SA due to a shoulder lesion was $0.8 \%(n=9963)$. A total of 7644 persons met the inclusion criteria for the current study. Compared with the study base, the study population was older, included relatively more women, had lower education, lived more often in the Eastern or
Northern part of Finland and worked more often in the public sector (table 1). They also had more commonly a manual occupation, a higher prevalence of physical work-related exposures and low job control.

\section{RTW and work participation}

A total of $76.9 \%$ of the persons in the study population returned to work sustainably, and the vast majority of them returned within 4 months. Median time to sustained RTW was 26.0 (95\% CI 24.7 to 27.3) days.

During the first year of follow-up, almost $80 \%$ of the time was spent at work, followed by $8 \%$ of the time on time-restricted full work disability (SA due to other reason than a shoulder lesion or temporary full disability retirement) (figure 1 , online supplementary table 1). About $7 \%$ of the time was spent unemployed or economically inactive. While being at work was the predominant work participation status throughout the follow-up time (declining from $77.7 \%$ to $46.7 \%$ ), after 5 years permanent disability retirement and after 10 years old-age retirement was the most common cause of reduced time at work. It is noteworthy that only a little time was spent on SA due to shoulder problems.

\section{Preterm exit from work}

During the 9-year follow-up, 1523 persons (19.9\% of the study population) left paid employment prior to the statutory retirement age of 63 years. A total of 1207 (15.8\%) persons received permanent disability retirement. The primary or secondary diagnosis of disability retirement was a shoulder lesion for 431 (35.7\%), a spine-related disease for 331 (27.4\%), osteoarthritis for 279 (23.1\%), a mental disorder for $196(16.2 \%)$, a neurological disease for $92(7.6 \%)$ and a cardiovascular disease for 78 persons $(6.5 \%)$. For $74.3 \%$, the primary or secondary cause was a musculoskeletal disease. In the study base population, 56740 persons (4.7\%) received permanent full disability pension; for $43.8 \%$ of the persons, the primary or secondary diagnosis was a musculoskeletal disease.

Male gender, age, a longer duration of initial SA due to the shoulder lesion, lower education, not being able to RTW sustainably and participation in vocational rehabilitation during the follow-up were associated with an increased risk of preterm exit from paid employment (table 2). The heavy lifting was associated with an increased risk of preterm exit in the age-adjusted and gender-adjusted model (model 1) but became borderline statistically significant in the fully adjusted model (model 2).

The associations between physical work-related factors and preterm exit from paid employment differed between the genders, heavy lifting showing a statistically significant association in women only and working with hands above shoulder level showing a marginal association in men (online supplementary table 2). In addition, participation in vocational rehabilitation was associated with a higher increase in the risk of preterm exit in women compared with men.

\section{Sensitivity analyses}

We ran sensitivity analyses to confirm the associations of the sector of employment and income with a preterm exit from employment (data not shown). The increased risk of preterm exit in the private sector became statistically significant after the inclusion of the duration of SA and participation in vocational rehabilitation. The relative risk estimates for income changed after the inclusion of education into model 1. 


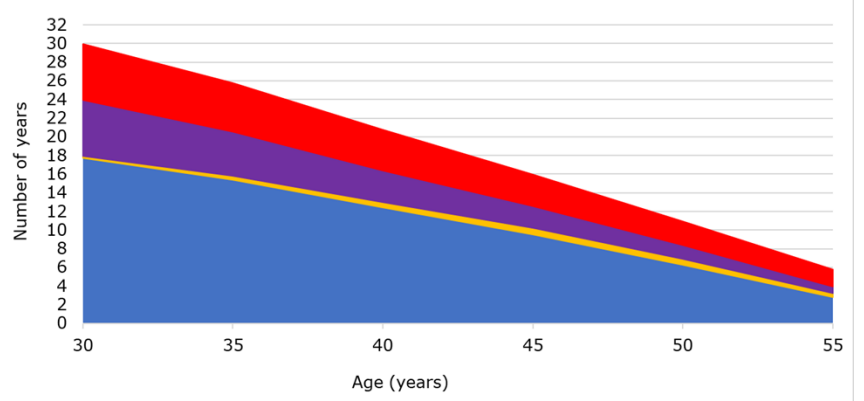

- Permanently out (on permanent disability retirement or preterm old age retirement) - Temporarily out (unemployed or being economically inactive) = On ill-health related benefit while having employment ॥t work

Figure 2 Years expected to be spent in different work participation statuses by the age of onset of the prolonged sickness absence due to a shoulder lesion.

\section{Working life expectancy}

Overall, persons with prolonged SA due to a shoulder lesion are expected to spend at work $35 \%-55 \%$ of their potential working life years. They are expected to lose about one-fifth (18\%-22\%) of their potential working life years due to disability retirement or preterm old-age retirement. For example, a person aged 30 years with a disabling shoulder disease will spend only 17.7 years at work, 6.0 years will be spent unemployed or economically inactive, another 6.0 years on retirement and 0.2 years on other ill health-related benefits (figure 2). Across all ages, women are expected to spend slightly more time at work and less time in unemployment compared with men (online supplementary figure $2 \mathrm{~A}$ and $\mathrm{B}$ ).

The working life expectancy among persons with a disabling shoulder disease is expected to be reduced by 1.8 (for those aged 55 ) to 8.1 (for those aged 30 ) years compared with that of the general population (figure 3 ). Across all ages, the difference in working life expectancy between persons with a shoulder lesion and the general population was larger for men than women (online supplementary figure 3 ). For example, at the age of 30 years, men and women with a shoulder lesion are expected to lose 8.9 and 6.8 years, respectively.

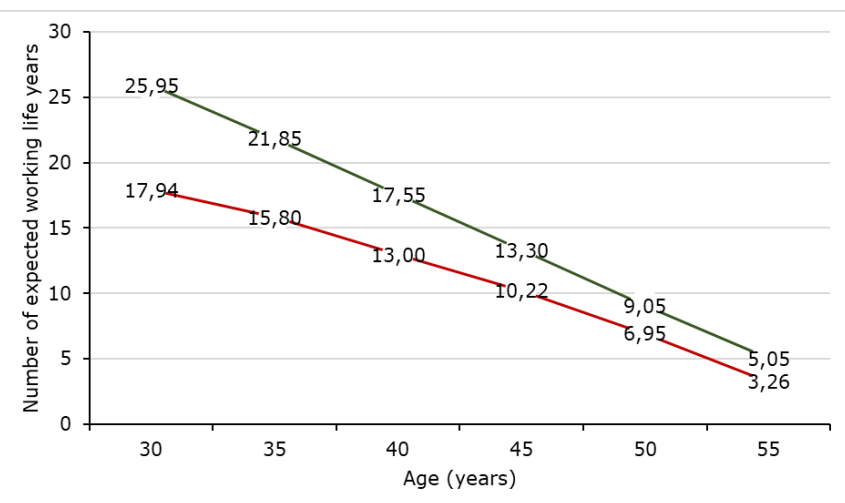

- -Persons with disabling shoulder lesion - -General Finnish population

Figure 3 Working life expectancy in 2006 among the general Finnish population (21) and persons with a disabling shoulder lesion (after a prolonged SA due to a shoulder lesion). SA, sickness absence.

\section{DISCUSSION}

This population-based study utilising data from national registers showed considerably reduced work participation among persons with a disabling shoulder lesion. Even though most of the persons returned to work within 4 months, their work participation during the 9-year follow-up was markedly reduced. Compared with the general population persons with a disabling shoulder disease are expected to lose from 1.8 to 8.1 years of working life, depending on their age. Permanent exit from paid employment was the main reason for the loss of working life years. Older age, male gender, lower education, a longer duration of initial SA due to the shoulder lesion, not being able to RTW sustainably and participation in vocational rehabilitation predicted a greater risk of preterm exit. Of work-related exposures, heavy lifting predicted preterm exit among women only.

\section{Comparison with previous studies}

Previous investigations in this field are rare. In the French COSALI study, utilising a random sample of workers attending a mandatory health examination, an upper limb disease was diagnosed in $12 \%$ of the participants. ${ }^{22}$ By the end of the follow-up of 5-7 years, $79.3 \%$ of them were still at work, while the corresponding share of the workers without any upper extremity pain at the baseline was $90.4 \%$. That study included workers with all kinds of upper extremity disorders. Rotator cuff syndrome was the largest diagnostic category; ${ }^{23}$ however, all diagnoses were combined in the analysis. Our results showing reducing work participation over time are in line with the results from the COSALI study, although there were major methodological differences between the studies. Moreover, retirement was the main route out of work in both studies.

Our results showed that persons with a disabling a shoulder lesion have a threefold risk of disability retirement compared with the general population. Our study population was older and included more persons with lower education and manual occupation than the general population. Previous studies have reported associations of age, education and manual occupation with the occurrence of work-related diseases, work disability and preterm exit from paid employment. ${ }^{12} 1424-26$

Shoulder lesions were the most common single cause of disability retirement; however, only a third of those who retired had a shoulder disease as the primary or secondary diagnosis for their retirement. Other common causes were low back diseases, osteoarthritis and mental disorders. Three out of four retired due to a musculoskeletal problem, indicating a considerable musculoskeletal comorbidity. Accordingly, prolonged work disability due to a shoulder problem should be considered as a risk indicator of future SA due to other musculoskeletal diseases or disability retirement due to any musculoskeletal disease.

Our results are in line with a previously published study reporting a high co-occurrence of shoulder pain with pain in other regions $(93 \%$ in the neck, $75 \%$ in forearm or hands, $50 \%$ in low back, $40 \%$ in knees and $44 \%$ in ankles or feet) in female kitchen workers. ${ }^{27}$ In our study, persons with a disabling shoulder lesion were more frequently exposed to heavy lifting than the general population. Heavy lifting is a known risk factor for low back pain and osteoarthritis, particularly in the knee and hip joint and could thereby explain the high musculoskeletal comorbidity observed in our study. ${ }^{28-30}$

Mental disorders were the second most common comorbid cause of disability retirement in our study. The result is in line with earlier findings on the co-occurrences of shoulder pain with mental problems and sleep disturbances. ${ }^{31} 32$ Although a 
relationship between cardiovascular risk factors (diabetes and smoking) and shoulder disorders was reported in a systematic review, ${ }^{33}$ the proportion of persons retired due to cardiovascular diseases was similar to that of the general population.

\section{Strengths and weaknesses}

Our study has several strengths. The nationally representative register data with complete information on ill-health-based benefits and employment/unemployment periods allowed to identify transitions between the different work participation statuses for each participant during the entire follow-up period. As the data were register based, there was no selection bias. Our findings can be generalised to societies with a relatively generous social security system.

Although with several strengths, this study had some limitations that need to be acknowledged. The diagnosis of a shoulder complaint is usually made in primary care based only on a clinical assessment. We chose the diagnosis M75 because its subgroups are partially overlapping and often not distinguishable in a clinical assessment. The lack of universally accepted diagnostic classification criteria, ${ }^{34}$ poor specificity of many physical examination tests ${ }^{35}$ and inconsistent diagnostic terminology ${ }^{36}$ may make the clinical diagnosis more or less inaccurate. In this study, we decided to rule out traumas because they were unsystematically recorded in the used registers. As a typical limitation of register-based studies, we lacked information on the time of onset or the severity of the condition, type of treatment, as well as medical rehabilitation. We also lacked lifestyle factors among our covariates. Therefore, some residual confounding may have remained in the model identifying determinants for preterm exit from paid employment.

In conclusion, our study showed that persons with disabling shoulder lesion are expected to lose a considerable number of their working life years mainly because of disability retirement due to musculoskeletal problems. Clinicians should consider interventions targeted at improving musculoskeletal functioning, and necessary work modifications before shoulder problems become chronic or the persons develop disabling comorbid musculoskeletal conditions.

Contributors All authors have contributed in planning the study design and revising the article. SS: has conducted the statistical analyses. MS: has done the most of the writing but especially SS and EV-J have strongly took part in writing, too. All authors have accepted the final version of the article.

Funding This study was funded by NordForsk (grant number 76659), the Finnish Work Environment Fund (grant number 115105), and by the Academy of Finland (grant number 303534).

\section{Competing interests None declared.}

Ethics approval The study was fully register-based and applied identification numbers pseudonymised by Statistics Finland. Research using such data does not need to undergo review by an ethics committee according to Finnish legislation.

Provenance and peer review Not commissioned; externally peer reviewed.

Open access This is an open access article distributed in accordance with the Creative Commons Attribution Non Commercial (CC BY-NC 4.0) license, which permits others to distribute, remix, adapt, build upon this work non-commercially, and license their derivative works on different terms, provided the original work is properly cited, appropriate credit is given, any changes made indicated, and the use is non-commercial. See: http://creativecommons.org/licenses/by-nc/4.0/.

\section{REFERENCES}

1 Jordan KP, Kadam UT, Hayward R, et al. Annual consultation prevalence of regional musculoskeletal problems in primary care: an observational study. BMC Musculoskelet Disord 2010;11:144

2 Silverstein B, Viikari-Juntura E, Kalat J. Use of a prevention index to identify industries at high risk for work-related musculoskeletal disorders of the neck, back, and upper extremity in Washington state, 1990-1998. Am J Ind Med 2002;41:149-69.
3 Croft P, Pope D, Silman A. The clinical course of shoulder pain: prospective cohort study in primary care. Primary care rheumatology society shoulder study group. BMJ 1996;313:601-2.

4 Luime JJ, Koes BW, Hendriksen IJ, et al. Prevalence and incidence of shoulder pain in the general population; a systematic review. Scand J Rheumatol 2004;33:73-81.

5 Cadogan A, Laslett M, Hing WA, et al. A prospective study of shoulder pain in primary care: prevalence of imaged pathology and response to guided diagnostic blocks. BMC Musculoskelet Disord 2011;12:119.

6 van der Windt DA, Koes BW, de Jong BA, et al. Shoulder disorders in general practice: incidence, patient characteristics, and management. Ann Rheum Dis 1995:54:959-64

7 van der Windt DA, Koes BW, Boeke AJ, et al. Shoulder disorders in general practice: prognostic indicators of outcome. Br J Gen Pract 1996;46:519-23.

8 Winters JC, Sobel JS, Groenier KH, et al. The long-term course of shoulder complaints: a prospective study in general practice. Rheumatology 1999;38:160-3.

9 Kuijpers T, van der Windt DA, van der Heijden GJ, et al. A prediction rule for shoulder pain related sick leave: a prospective cohort study. BMC Musculoskelet Disord 2006:7:97.

10 Desmeules F, Braën C, Lamontagne $M$, et al. Determinants and predictors of absenteeism and return-to-work in workers with shoulder disorders. Work 2016;55:101-13.

11 Engebretsen K, Grotle M, Bautz-Holter E, et al. Predictors of shoulder pain and disability index (SPADI) and work status after 1 year in patients with subacromial shoulder pain. BMC Musculoskelet Disord 2010;11:218.

12 Pekkala J, Rahkonen 0, Pietiläinen 0, et al. Sickness absence due to different musculoskeletal diagnoses by occupational class: a register-based study among 1.2 million Finnish employees. Occup Environ Med 2018;75:296-302.

13 van der Molen HF, Foresti C, Daams JG, et al. Work-related risk factors for specific shoulder disorders: a systematic review and meta-analysis. Occup Environ Med 2017;74:745-55

14 Sundstrup E, Hansen ÅM, Mortensen EL, et al. Retrospectively assessed physical work environment during working life and risk of sickness absence and labour market exit among older workers. Occup Environ Med 2018;75:114-23.

15 Solovieva S, Kontio T, Viikari-Juntura E. Occupation, physical workload factors, and disability retirement as a result of hip osteoarthritis in Finland, 2005-2013. J Rheumatol 2018:45:555-62.

16 Kjellberg K, Lundin A, Falkstedt D, et al. Long-term physical workload in middle age and disability pension in men and women: a follow-up study of Swedish cohorts. Int Arch Occup Environ Health 2016;89:1239-50.

17 Ropponen A, Svedberg P, Koskenvuo M, et al. Physical work load and psychological stress of daily activities as predictors of disability pension due to musculoskeletal disorders. Scand J Public Health 2014:42:370-6.

18 Solovieva S, Pehkonen I, Kausto J, et al. Development and validation of a job exposure matrix for physical risk factors in low back pain. PLoS One 2012;7:e48680.

19 Solovieva S, Pensola T, Kausto J, et al. Evaluation of the validity of job exposure matrix for psychosocial factors at work. PLoS One 2014;9:e108987.

20 Sullivan DF. A single index of mortality and morbidity. HSMHA Health Rep 1971;86:347-54

21 Nurminen M. Working-life expectancy in Finland: trends and differentials 2000-2015 Helsinki: A Multistate Regression Modeling Approach, Helsinki: Finnish Centre for Pensions, 2012

22 Sérazin C, Ha C, Bodin J, et al. Employment and occupational outcomes of workers with musculoskeletal pain in a French region. Occup Environ Med 2013;70:143-8.

$23 \mathrm{Ha} \mathrm{C}$, Roquelaure Y, Leclerc A, et al. The French musculoskeletal disorders surveillance program: pays de la loire network. Occup Environ Med 2009:66:471-9.

24 Reeuwijk KG, van Klaveren D, van Rijn RM, et al. The influence of poor health on competing exit routes from paid employment among older workers in 11 European countries. Scand J Work Environ Health 2017:43:24-33.

25 Alavinia SM, Burdorf A. Unemployment and retirement and ill-health: a cross-sectional analysis across European countries. Int Arch Occup Environ Health 2008;82:39-45.

26 van den Berg T, Schuring M, Avendano $M$, et al. The impact of ill health on exit from paid employment in Europe among older workers. Occup Environ Med 2010;67:845-52

27 Haukka E, Leino-Arjas P, Solovieva S, et al. Co-occurrence of musculoskeletal pain among female kitchen workers. Int Arch Occup Environ Health 2006;80:141-8.

28 Coenen P, Gouttebarge V, van der Burght AS, et al. The effect of lifting during work on low back pain: a health impact assessment based on a meta-analysis. Occup Environ Med 2014;71:871-7

29 Jensen LK. Knee osteoarthritis: influence of work involving heavy lifting, kneeling, climbing stairs or ladders, or kneeling/squatting combined with heavy lifting. Occup Environ Med 2008:65:72-89.

30 Jensen LK. Hip osteoarthritis: influence of work with heavy lifting, climbing stairs or ladders, or combining kneeling/squatting with heavy lifting. Occup Environ Med 2008;65:6-19.

31 Cho CH, Jung SW, Park JY, et al. Is shoulder pain for three months or longer correlated with depression, anxiety, and sleep disturbance? J Shoulder Elbow Surg 2013;22:222-8.

32 Rajala U, Keinänen-Kiukaanniemi S, Uusimäki A, et al. Musculoskeletal pains and depression in a middle-aged finnish population. Pain 1995;61:451-7. 
33 Viikari-Juntura E, Shiri R, Solovieva S, et al. Risk factors of atherosclerosis and shoulder pain--is there an association? A systematic review. Eur J Pain 2008; 12:412-26.

34 Boocock MG, Collier JM, McNair PJ, et al. A framework for the classification and diagnosis of work-related upper extremity conditions: systematic review. Semin Arthritis Rheum 2009;38:296-311.
35 Lange T, Matthijs 0 , Jain NB, et al. Reliability of specific physical examination tests for the diagnosis of shoulder pathologies: a systematic review and meta-analysis. $\mathrm{Br}$ Sports Med 2017; 51:511-8.

36 Schellingerhout JM, Verhagen AP, Thomas S, et al. Lack of uniformity in diagnostic labeling of shoulder pain: time for a different approach. Man Ther 2008:13:478-83. 